\title{
Health care transition in Germany - standardization of procedures and improvement actions
}

\author{
This article was published in the following Dove Press journal: \\ Journal of Multidisciplinary Healthcare \\ I July 201 I \\ Number of times this article has been viewed
}

\section{Claudia Pieper \\ Izabela Kolankowska \\ Institute for Medical Informatics, Biometry and Epidemiology, University Hospital of Essen, Essen, North Rhine-Westphalia, Germany}

Correspondence: Claudia Pieper Institute for Medical Informatics, Biometry and Epidemiology, University Hospital of Essen, Hufelandstrasse 55, 45I 22 Essen, North Rhine-Westphalia, Germany

Tel +4920I 7234504

Fax +4920I 7235933

Email claudia.pieper@uk-essen.de
Abstract: Previous studies have assessed an increase in the number of people in need and emphasized the advantages of structured discharge management and health care transition. Therefore, our study evaluated the status quo of transition in a major German city after standardization of procedures and implementation of standard forms. Satisfaction with handling of standard forms and improvement of procedures was evaluated. Additionally, patients who had recently been hospitalized were asked about the hospital discharge process. The results show that the recent efforts of standardization helped to improve interface management for health care workers and patients and showed further improvement options.

Keywords: hospital discharge process, standard forms, long-term care, aftercare

\section{Introduction}

An increase in life expectancy causes a demographic change worldwide. In the next five decades, the number of people aged 65 and older will increase from 17\% in 2002 to $30 \%$ in $2050 .{ }^{1}$ A study by Schulz et $\mathrm{al}^{2}$ predicted an increase in the number of people in need of care by 1 million for the next 20 years. The increase in the number of older people and the burden of chronic diseases will have a substantial impact on health care systems.

There is a trend in countries using diagnosis-related groups (DRGs) to shorten the length of hospital stay because DRG flat-rate payments induce an efficient resource management. ${ }^{3}$ The reduction of the length of stay in hospitals will also change requirements for caregivers, physicians, and aftercare institutions such as rehabilitation hospitals, physiotherapists, and others. ${ }^{4}$ A shorter length of stay does not automatically lead to reduced medical costs, because of intensified treatment and nursing efforts. Close cooperation between sectors is needed to meet these requirements. ${ }^{5}$

A wide net of hospitals and physicians is established in Germany. Medical facilities are appropriately equipped and the statutory health insurance system provides nearly full coverage for many medical treatments and medications. Independent of social status, nearly everybody in Germany has access to this system. Most people see a general practitioner (GP) at the first sign of health problems and they are free to see the GP of their choice. Thus, GPs are often the first point of contact for patients. If necessary, the GP refers patients to a specialist or a clinic. All hospitals in Germany, except for private clinics, offer services for insured patients. In many respects, the Long-Term Care Insurance Program (LTCI) in Germany follows the established model of health insurance for people in need of long-term care. It offers two kinds of 
assistance: professional home care/nursing home services or cash allowances. ${ }^{6}$ In Germany, people are assigned to one of three care levels according to the severity of need. A total of 2.13 million people in Germany required long-term care in 2005 . The majority ( $82 \%$ ) of them were aged 65 years or older, while one-third (33\%) were aged 85 years or older. ${ }^{7}$ The long-term care costs in Germany in 2007 were equal to $0.9 \%$ of the gross domestic product. ${ }^{8}$

The term "health care transition" refers to the movement of patients (mostly elderly) between health care settings. This project focused on adults and the elderly, because health care transition for young people usually requires attention to other areas of life.

The American Geriatrics Society defines transitional care as "a set of actions designed to ensure the coordination and continuity of health care as patients transfer between different locations or different levels of care within the same location ... Transitional care, which encompasses both the sending and the receiving aspects of the transfer, is essential for persons with complex care needs". 9 Previous studies emphasize the advantages of discharge management and structured health care transition, which can contribute to the reduction of rehospitalization rates. ${ }^{10}$ Furthermore, patients wish to be informed about the treatment process and to be accompanied from discharge to aftercare. ${ }^{11}$

In Germany, the national nursing discharge guidelines Expertenstandard Entlassungsmanagement in der Pflege ${ }^{12}$ were defined to optimize existing approaches for structured discharge processes. It postulates an interdisciplinary approach including all heath care professionals.

The mission of the Health Care Transition Initiative in Essen, Germany, assigned by the local public health department, was to promote cooperative efforts to improve the process of transitioning for health care workers and patients. The aim of the project was to optimize the transition process for all patients, with a focus on the elderly.

Members of the Health Care Transition Initiative in Essen were hospital physicians and GPs as well as caregivers, social workers, and health insurance representatives. They worked together for about 3 years, focusing on improving health care transition in the city of Essen. Essen has approximately 585,000 inhabitants and is the sixth-largest city in Germany. The aim of this project was to standardize procedures in practice and care delivery systems to improve transition for health care workers as well as for patients.

Activities carried out through or assigned by the Health Care Transition Initiative included standardization of procedures by developing standard forms as well as networking, literature research, and evaluation. The standard forms should provide the most important information needed for patient transition between care settings. All standard forms are available for download on the Health Portal Web site of Essen (http://essen.de/de/Gesundheit/Startseite_Gesundheit.jsp).

Two years ago, the following standard forms, which are either electronic or paper-based, were implemented:

- a standard form to fax for additional information between practices and hospitals

- a standard form checklist for hospital discharge

- a standard transition form

- a standard short form for a doctor's report.

The Health Care Transition Initiative scheduled an independent scientific evaluation of the standard forms. The evaluation was based on Expertenstandard Entlassungsmanagement in der Pflege. ${ }^{12}$

The purpose of our study was to support innovative interdisciplinary research in this field of health care, to improve the quality of health care by evaluation-implemented strategies, and to identify gaps between current and optimal performance, and patient outcomes. Therefore, we investigated the impact of standardization on interface management and on the quality of the transition processes for patients by assessing:

- the degree of utilization of the standard forms

- the acceptance of the standard forms

- reasons for not using the standard forms

- improvement of workload

- improvement of communication

- patient satisfaction regarding discharge

- whether there was a relation between utilization of the standard forms and patient satisfaction.

\section{Methods}

Nursing institutions, hospitals, and GPs in Essen were surveyed to evaluate the use of the standard forms (copies of the questionnaires are available on request). Variables concerning degree of utilization, health care workers' satisfaction with handling of standard forms, and assessment of improvement of procedures were evaluated using a standardized questionnaire. Because GPs solely use the standard form to fax and the standard short form as a doctor's report, they received a questionnaire concerning only these forms. Nursing institutions and hospitals received a questionnaire concerning all standard forms. Each topic was introduced with an opening question. Important topics were evaluated by using closed questions. We used open questions to let respondents describe their primary concerns. The questionnaires were pretested before using them in the survey. 
Sixteen hospitals as well as 110 further medical institutions (nursing homes and services, rehabilitation clinics) and 116 GPs (Association of Statutory Health Insurance Physicians, representatively) had been previously informed about the evaluation. The questionnaires were sent in a second step.

In an additional patient survey we evaluated parameters concerning quality of treatment and satisfaction with hospital discharge using a standardized questionnaire. The name of the hospital, reasons for hospitalization, and sociodemographic information were obtained. Patients who had recently been hospitalized with a discharge date in March or April 2008, were aged 18 years or older, and who had a length of stay of 2 days or more were included. Patients with dementia, intensive care patients, and those who were not able to understand the language were excluded according to the study protocol. Family members could fill out the questionnaire if a patient was not able to because of physical limitations or the like. The nursing staff of each hospital in Essen distributed 300 questionnaires to randomly selected patients, irrespective of the use of standard forms in these units. Questionnaires included information for patients about the survey, the overall project, and privacy protection. The patient survey was anonymous and questionnaires were sent to the study center in a pre-addressed and postal paid envelope. The questionnaire was pretested before using it in the survey. Each topic was introduced with an opening question. We used closed questions as well as open questions to let patients describe their primary concerns.

Proportions were expressed as percentages. Values of satisfaction ratings were compared between the different sectors using SPSS (v 14.0; SPSS, Inc, Chicago, IL). To measure the degree of correlation between patient satisfaction and the utilization of the standard forms, Pearson's correlation test was used. All metric data are presented as means ( \pm standard deviation). For comparison of groups, the Wilcoxon signed-rank test was used for continuous variables, Fisher's exact test for dichotomous variables, and the $\chi^{2}$-test for ordinal variables. An $\alpha$ error $(P)$ of less than 5\% was considered significant.

\section{Results}

Of 116 nursing institutions and hospitals, 82 participated in the survey ( $65 \%$ response rate). Of the 116 GPs, 27 sent back the questionnaire (23\% response rate). The response rate of the patient survey was $13 \%(n=634)$, whereas there was a spread among hospitals from $1 \%$ to $25 \%$. The response rates for both surveys are shown in Table 1.
Table I Response rates

\begin{tabular}{llcl}
\hline & Frequency & $\%$ & Addressed \\
\hline Response rate: hospitals, & nursing & institutions, & and \\
Hospitals & 13 & 81 & 16 \\
Nursing homes & 41 & 63 & 110 \\
Nursing services & 27 & & \\
Rehabilitation clinics & 1 & & \\
All & 82 & 57 & 143 \\
General practitioners & 27 & 23 & 116 \\
All & 109 & 42 & 259 \\
Response rate: patients & & & \\
All & 634 & 13 & 4800 \\
\hline
\end{tabular}

\section{Results of hospitals, nursing institutions, and GPs Degree of utilization of the standard form}

Of 81 nursing institutions and hospitals, 77 were aware of the new standard forms; of 27 GPs, this number was 13 . The standard forms had been implemented in 65 nursing institutions and hospitals and in nine practices. Of these institutions and practices, 55\% used paper-based standard forms, 7\% used the electronic version, and $18 \%$ used both options. Of these, $80 \%$ used the standard transition form, $60 \%$ used the standard form checklist, 19\% used the standard short form, and $33 \%$ used the standard form to fax. More than half of the GPs used the paper-based forms. There was no relationship between the number of staff and the degree of utilization of the standard forms.

\section{Acceptance of the standard forms/ improvement of workload}

Along with increasing rates of acceptance, reduction of work was reported more frequently. We performed a $\chi^{2}$-test for the two groups, "reduction of work - yes" and "reduction of work - no", regarding the number of answers about acceptance. No statistically significant relationship was found with this test $(P=0.313)$ or when using Spearman's correlation $(P=0.154)$. An overview of the acceptance and improvement of procedures is given in Table 2.

Table 2 Acceptance of standard forms and reduction of work

\begin{tabular}{lllll}
\hline \multirow{4}{*}{} & \multicolumn{3}{l}{ Reduction of work } \\
\cline { 3 - 5 } & No & Yes & No change \\
\hline \multirow{2}{*}{ Acceptance } & Very high/high & $6(35 \%)$ & $18(60 \%)$ & $9(50 \%)$ \\
& Moderate & $6(35 \%)$ & $9(30 \%)$ & $9(50 \%)$ \\
& Low/very low & $5(30 \%)$ & $3(10 \%)$ & $0(0 \%)$ \\
\multirow{2}{*}{ All } & Not available & - & - & - \\
\hline & & $17(100 \%)$ & $30(100 \%)$ & $18(100 \%)$ \\
\hline
\end{tabular}




\section{Reasons for not using standard forms}

Where standard forms were not used, $86 \%$ of all respondents reported reasons for this. Principle reasons against using the standard form to fax, the standard form checklist for hospital discharge, and the standard transition form were the time and effort required to fill them out, as well as a lack of clarity. Further causes were lack of information about the standard forms and problems with the electronic version.

Nursing services used own transition forms and/or own short forms in addition to the standard forms ( $41 \%$ of all nursing services) and ten hospitals (63\% of all hospitals) used their own checklists and/or short forms.

\section{Improvement of communication}

Concerning the improvement of communication and information exchange among hospitals, nursing institutions, and GPs, $47 \%$ of the hospitals, $32 \%$ of nursing homes, and $26 \%$ of nursing services specified improved information exchange.

Regarding exchange of work experience, hospitals reported a regular exchange of work experience with colleagues from other institutions in $36 \%$ of cases, while nursing homes and nursing services reported a regular exchange in $31 \%$ overall.

\section{Results of patient survey}

The mean age of the 634 patients (296 males, 312 females, 26 unknown sex) was $62 \pm 15$ years. Of the patients, $4 \% \mathrm{did}$ not report sex or age, $39 \%$ were in retirement, and $45 \%$ had completed at least 9 years of basic education (lower secondary school level). The other patients had either a high school

Table 3 Sociodemography

\begin{tabular}{llll}
\hline & & Frequency & $\%$ \\
\hline Gender & Female & 312 & 49 \\
& Male & 296 & 47 \\
Family status & N/A & 26 & 4 \\
& Single & 74 & 12 \\
& Divorced & 57 & 9 \\
& Married & 392 & 62 \\
& Widowed & 83 & 13 \\
Children & N/A & 28 & 4 \\
& None & 91 & 14 \\
& One & 157 & 25 \\
& More than two & 304 & 48 \\
Living arrangement & N/A & 82 & 13 \\
& Not living alone & 434 & 69 \\
& Living alone & 170 & 27 \\
& N/A & 30 & 5 \\
\hline
\end{tabular}

Abbreviation: N/A, not available. or a college education. A summary of the family status and living arrangement is given in Table 3.

In our study, 146 (25\%) patients made use of personal care after hospitalization: 66 patients reported making use of nursing homes and nursing services and 80 patients reported making use of care from neighbors and family members. In total, 102 patients were discharged from hospital into rehabilitation. Thirty-four patients $(15 \%)$ had already been assigned to one of three care levels according to the severity of need and 15 (3\%) wanted to apply for a care level that provided coverage for care benefits.

Of the patients, $78 \%$ reported that a discharge interview was very important to them and $80 \%$ had a discharge interview with a physician ( $78 \%$ of these were with a ward physician). Seventy-one percent received a discharge letter, used to summarize a hospital stay and addressed to the patient's GP. Additionally, 21\% of the patients received laboratory values, $32 \%$ obtained reports, and $14 \%$ obtained $\mathrm{X}$-ray images.

\section{Patient satisfaction regarding discharge}

Of the 504 patients who reported their assessment, 385 $(77 \%)$ of these patients described their discharge as good, $21 \%$ described it as slightly problematic or problematic, and $2 \%$ described it as very problematic.

\section{Relationship between utilization of the standard forms and patient satisfaction}

Figure 1 shows the rates of distribution of GPs' information about patients' aftercare stratified by use of standard forms: in hospitals where the standard forms were not used, half $(46 \%)$

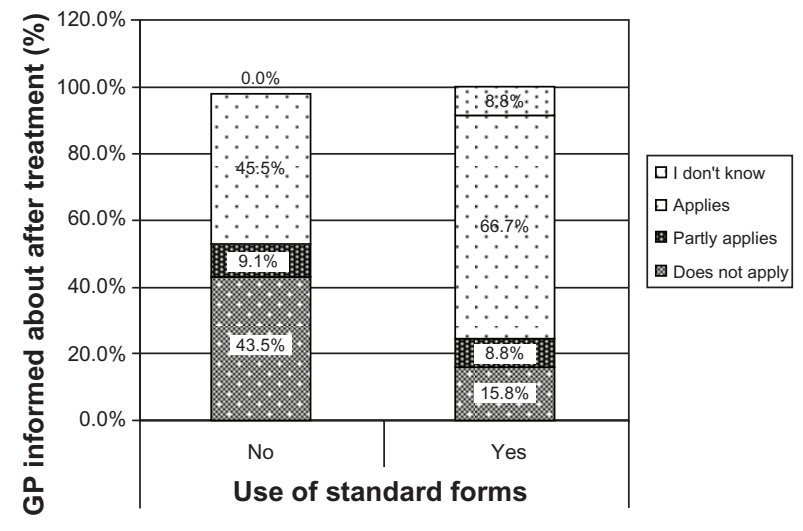

Figure I Use of standard forms and general practitioners' information about aftercare.

Note: Percentages do not add up to $100 \%$ because $n /$ a category is not shown. 
of the patients reported that their GP was not informed about their after-treatment. In hospitals where the standard forms were used, $16 \%$ of the patients reported that their GP was not informed about their after-treatment. Two-thirds (67\%) of those patients reported that their GP was informed vs 45\% in the other group.

There was a statistically significant relationship between the implementation of standard forms and GPs' information about aftercare: more patients coming from hospitals using standard forms stated that their GP was informed about aftercare (Wilcoxon signed-rank test, $P=0.021$ ).

\section{Discussion}

The aim of the Health Care Transition Initiative in Essen, Germany, was to improve procedures by standardization. This initiative was an interdisciplinary approach involving both medical and nursing professionals and, additionally, patients. Our study evaluated the impact of an adapted health care transition guide on interface management and patients' perceived quality of care to support innovative interdisciplinary research in this field of health care.

Evaluation of posthospital demands is of great importance but is carried out infrequently. ${ }^{5}$ But it has to be ensured that follow-up care providers receive information to assess a patient and create an informed follow-up care plan. For example, the doctor's report provides information about clinical findings and appropriate (drug) therapy as well as needs of medical supplies and in- and outpatient care.

An optimal transition process can avoid inconsistencies in health care for the patient. ${ }^{13}$ Studies have shown that communication with patients or family members is the most important factor in health care transition. Well-informed patients are more satisfied with the transition process. ${ }^{14,15}$ A structured discharge process implies standardization of procedures and responsibilities. ${ }^{16}$ However, hospitals, nursing institutions, and GPs use a multitude of different forms or even forgo using forms. Refusal to use forms indicates deficits in communication among health care professionals. Providing information for health care professionals in hospitals about the status of the health care transition could raise the GPs' and hospital physicians' awareness: in Essen, three-quarters of the institutions initially agreed to participate in standardization activities.

Kripalani et $a{ }^{17}$ stated the advantages of providing flexible solutions regarding information exchange. In our study, more than half of the institutions and practices used paper-based standard forms, only $7 \%$ used the electronic version, and $18 \%$ used both options to ensure timely information.

Currently, 64 (77\%) of the participating institutions implemented the guide and used the standard forms. The workload improvement was reported as strong by one-third of all health care workers and as moderate by one-third. Half of the hospitals and one-third of the nursing homes reported enhanced exchange of information. We focused on hospitalization- and discharge-related communication, but other aspects of communication may also require improvement. Many GPs are not routinely informed about their patients' hospital course; on the other hand, many GPs may not provide enough information to hospitals on their part. ${ }^{18}$

Additional to the standard forms, forms developed in-house were used by $63 \%$ of the hospitals, $41 \%$ of the nursing institutions, and $24 \%$ of the GPs. However, these institutions did not generally refuse to use standard forms if the requirements were met. In particular, improvement of data processing has to be adapted.

\section{Conclusion}

Our study is limited by the cross-sectional design and the response rates from GPs and patients. In contrast to a $65 \%$ response rate from hospitals and nursing institutions in our study, the low response rate for GPs possibly shows low interest in this topic. Our patient respondents may not be representative but, nevertheless, with a large absolute number of 634 patients, we may have collected answers from a variety of patients being hospitalized in the city of Essen at this time.

Furthermore, we focused on evaluating the transition process itself and therefore we cannot draw any conclusion about quality indicators such as mortality and morbidity, rehospitalization, and medication errors. Shepperd et $\mathrm{al}^{19}$ showed in a meta-analysis of randomized controlled trials that rehospitalization in elderly patients depends on discharge planning: rehospitalization rates and length of stay were lower in a structured discharge process. The impact on mortality and medical costs remains unclear. ${ }^{19}$ Similarly, another study showed decreased mortality rates for elderly patients when discharge was linked with a long-term treatment plan. ${ }^{20}$ Kripalani et $\mathrm{al}^{17}$ found infrequent communication between hospitals and GPs as well as a lack of documentation in discharge.

The patient survey in this study reflected relatively high satisfaction with discharge when the standard forms were used. Patient responses indicated that the higher the level of implementation the more follow-up care providers were 
informed about patients' needs. These findings are consistent with those in other studies, such as Weinberger et al. ${ }^{21}$ Therefore, we assume that increased levels of patient satisfaction are related to a structured transition process.

Summing up the results of the evaluation, the following aspects had to be further discussed by the Health Care Transition Initiative:

- Public relation actions giving further information for physicians and health care workers have to be carried forward.

- A total of six GPs and 30 institutions (three hospitals and 27 nursing homes and services) were interested in a closer cooperation with the Health Care Transition Initiative and will be included in further activities.

- The evaluation gives the possibility for the development of a quality management of health care transition in Essen and beyond.

In 2008, the city of Essen awarded the Health Care Transition Initiative with the Honour Award for Nursing. Meanwhile, other cities in North Rhine-Westphalia took over the guide and the standard forms.

However, the successful implementation of standardizations of procedures requires a more detailed understanding of the broader patterns and pathways. A greater understanding of the transition processes is needed, especially for hospitals and GPs. To evaluate patient-related outcomes in the long run, further research activities should focus on the assessment of quality indicators in the management of health care transition.

\section{Acknowledgments}

The authors thank the participating hospitals, nursing institutions, physicians, and patients for their contribution to the study.

\section{Disclosure}

The Ministry for Labor, Health and Social Affairs of North Rhine-Westphalia [64-V42A-3062] funded this work. The ethical committee of the University of Duisburg-Essen approved the study. Dr Claudia Pieper conceived of the study and participated in its design, coordination, and data collection and drafted the manuscript. Izabela Kolankowska participated in the design of the study and data collection, performed the statistical analysis under the supervision of Dr Pieper, and provided administrative support. All authors have critically reviewed the content and have approved the final version submitted for publication. The authors report no conflicts of interest in this work.

\section{References}

1. Ulrich RE. Demographic change in Germany and implications for the health system. J Public Health. 2004;13(1):10-15.

2. Schulz E, Leidl R, König H-H. Starker Anstieg der Pflegebedürftigkeit zu erwarten: Vorausschätzungen bis 2020 mit Ausblick auf 2050. Wochenbericht. 2001;68(5):65-77. [German].

3. Lüngen M, Lauterbach K, editors. Ergebnisorientierte Vergütung bei DRG: Qualitätssicherung bei pauschalierender Vergütung stationärer Krankenhausleistung [Result-Oriented Remuneration for DRG: quality assurance in inpatient hospital blanket compensation benefits]. Berlin: Springer; 2002. [German].

4. Wingenfeld K. Grenzen der Evidenzbasierung komplexer pflegerischer Standards am Beispiel des Entlassungsmanagements. Pflege and Gesellschaft. 2004;3:79-84. [German].

5. Bräutigam C, Klettke N, Kunstmann W, et al. Versorgungskontinuität durch Pflegeüberleitung? Ergebnisse einer teilnehmenden Beobachtung [Continuity of care by Pflegeüberleitung? Results of participant observation]. Pflege. 2005;18(2):112-120. [German].

6. Evers A. The new Long-Term Care Insurance Program in Germany. J Aging Soc Policy. 1998;10(1):77-98.

7. Destatis.de [homepage on the Internet]. People in need of long-term care: the present and the future. Published November 7, 2008. Available from: http://www.destatis.de/. Accessed May 5, 2011.

8. Wip-pkv.de [homepage on the Internet]. Die Pflegefinanzierung und die Pflegeausgaben im internationalen Vergleich. WIP-Diskussionspapier 2/10. Published June 2010. Available from: http://www.wip-pkv.de/. Accessed May 5, 2011.

9. Coleman EA, Boult CE, for the American Geriatrics Society Health Care Systems Committee. Improving the quality of transitional care for persons with complex care needs. J Am Geriatr Soc. 2003; 51(4):556-557.

10. Österreichisches Bundesministerium für Gesundheit und Frauen, ed. Schnittstellenmanagement zwischen ambulanter und stationärer Versorgung. Vienna: Endbericht; 2005. [German].

11. Uhlmann B, Bartel D, Kunstmann W, et al. Versorgungskontinuität durch Pflegeüberleitung: Die Perspektive von Patienten und Angehörigen [Continuity of care: the perspective of patients and their relatives]. Pflege. 2005;18(2):105-111. [German].

12. Deutsches Netzwerk für Qualitätsentwicklung in der Pflege (DNQP), ed. Schriftenreihe des Deutschen Netzwerks für Qualitätssicherung in der Pflege: Expertenstandard Entlassungsmanagement in der Pflege. Osnabrück: DNQP; 2004. [German].

13. Höhmann U, Müller-Mundt G, Schulz B. Patientenorientierte Versorgungskontinuität. Überleitungspflege: Möglichkeiten und Grenzen [Patient-oriented quality of care: opportunities and limitations]. Die Schwester Der Pfleger. 1997;1:27-32. [German].

14. Schönlau K, Kunstmann W, Plenter C, et al. Versorgungskontinuität: die Perspektive von Pflegeüberleitungskräften [Continuity of care: the perspective of nurses responsible for Pflegeüberleitung]. Pflege. 2005;18(2):95-104. [German].

15. Grundböck A, Rappauer A, Müller G, et al. Ausgewählte Ergebnisse einer Evaluationsstudie über ein Wiener Modellprojekt: Entlassungsmanagement durch ambulante Pflegepersonen; Sicht der Patienten und Angehörigen [Selected results of an evaluation study on a Viennese model project: discharge management in hospitals by home care nurses; the view of patients and their families]. Pflege. 2005;18(2):121-127. [German].

16. Jha AK, Orav EJ, Epstein AM. Public reporting of discharge planning and rates of readmissions. $N$ Engl J Med. 2009;361(27):2637-2645.

17. Kripalani SF, LeFevre F, Phillips CO, et al. Deficits in communication and information transfer between hospital-based and primary care physicians: implications for patient safety and continuity of care. JAMA. 2007;297(8):831-841.

18. Pantilat SZ, Lindenauer PK, Katz PP, et al. Primary care physician attitudes regarding communication with hospitalists. Am J Med. 2001; 111(Suppl):S15-S20. 
19. Shepperd S, McClaran J, Phillips CO, et al. Discharge planning from hospital to home. Cochrane Database Syst Rev. 2010;1:CD000313.

20. Damiani, G, Federico B, Venditti A, et al. Hospital discharge planning and continuity of care for aged people in Italian local health unit: does the care-home model reduce hospital readmission and mortality rates? BMC Health Serv Res. 2009;9:22.
21. Weinberger M, Oddone EZ, Henderson WG. Does increased access to primary care reduce hospital readmissions? Veterans Affairs Cooperative Study Group on Primary Care and Hospital Readmission. N Engl J Med. 1996;334(22):1441-1447.

\section{Publish your work in this journal}

The Journal of Multidisciplinary Healthcare is an international, peerreviewed open-access journal that aims to represent and publish research in healthcare areas delivered by practitioners of different disciplines. This includes studies and reviews conducted by multidisciplinary teams as well as research which evaluates the results or conduct of such teams or healthcare processes in general. The journal covers a wide range of areas and welcomes submission from practitioners at all levels, from all over the world. The manuscript management system is completely online and includes a very quick and fair peer-review system. Visit http://www.dovepress.com/testimonials.php to read real quotes from published authors.

Submit your manuscript here: http://www.dovepress.com/journal-of-multidisciplinary-healthcare-journal 